\title{
A educação do campo em Ji-Paraná, RO: a mesmidade e a interdição de identidades camponesas
}

\author{
Rural education in Ji-Paraná, RO: sameness and the prohibition of \\ rural identities

\section{L'éducation à la campagne à Ji-Paraná, RO: l'uniformité et l'interdiction des identités paysannes}

\section{La educación de campo en Ji-Paraná, RO: la mismidad y la prohibición de identidades campesinas}

\author{
Alberto Dias Valadão ${ }^{1}$ \\ José Licínio Backes² \\ Recebido em 05/05/2017; revisado e aprovado em 08/05/2017; aceito em 08/05/2017 \\ DOI: http://dx.doi.org/10.20435/inter.v19i2.1597
}

\begin{abstract}
Resumo: O presente trabalho, inspirado nos Estudos Culturais, faz uma análise das proposições docentes sobre as práticas que devem ser desenvolvidas para o fortalecimento da Educação do Campo no município de Ji-Paraná, RO. Mostra-se que as identidades camponesas tendem a continuar sendo padronizadas porque os sujeitos do campo não participam do processo de elaboração da educação que a eles se destina.
\end{abstract}

Palavras-chave: educação do campo; estudos culturais; práticas curriculares.

Abstract: This paper, grounded on Cultural Studies, performs an analysis of teachers' propositions about the practices that should be developed to strengthen the rural education in Ji-Paraná, RO. It shows that rural identities tend to be standardized because the rural subjects do not participate in the process of designing their own education.

Keywords: rural education; cultural studies; curriculum practices.

Résumé: Ce travail, inspiré par les Études Culturelles, présente l'analyse des propositions de l'enseignement sur les pratiques qui doivent être développées pour renforcer l'éducation à la campagne dans la ville de JiParaná, RO. II est démontré que les identités paysannes ont une tendance à rester standardisées pour ne pas compter sur la participation de sujets sociaux auxquels cette éducation est destinée.

Mots-clés: éducation à la campagne; études culturelles; les pratiques pédagogiques.

Resumen: Este trabajo, inspirado en Estudios Culturales, hace un análisis de las proposiciones docentes sobre las prácticas que deben ser desenvueltas para el fortalecimiento de la educación de campo en el municipio de Ji-Paraná, RO. Se muestra que las identidades campesinas tienden a continuar siendo padronizadas porque los sujetos del campo no participan del proceso de elaboración de su educación.

Palabras clave: educación de campo; estudios culturales; prácticas curriculares.

\section{INTRODUÇÃO}

O estado de Rondônia, após 34 anos de emancipação política, continua apresentando no seu interior características eminentemente agrícolas em seu sistema produtivo, especialmente na agricultura e pecuária, que concorriam recentemente com o extrativismo vegetal e mineral. Isso se deve à aceleração do seu processo de povoamento no início da década de 1980. Agricultores pobres de estados principalmente do Sudeste e do Sul foram encorajados pelas campanhas publicitárias do Governo Federal com a promessa de encontrar no novo "eldorado" a melhoria das condições de vida, mas enfrentaram dificuldades, como "[...] transporte deficiente, clima

\footnotetext{
${ }^{1}$ Universidade Federal de Rondônia (UNIR), Campus de Ji-Paraná, Rondônia, Brasil.

2 Universidade Católica Dom Bosco (UCDB), Campo Grande, Mato Grosso do Sul, Brasil.
} 
insalubre, febre amarela, malária, precárias condições de sobrevivência sem as mínimas condições de higiene [...]" (CIM, 2003, p. 9).

A ocupação do interior do estado, que foi sendo feita ao longo da BR-364, deu-se, portanto, por causa da agropecuária desenvolvida em pequenos lotes de terra, em sua maioria de 21 ou 42 alqueires. Por isso, quando se observa a distribuição da população dentro do estado, se vê uma diferença em relação aos números do país no que tange ao êxodo para o espaço urbano. Segundo dados do Instituto Brasileiro de Geografia e Estatística (IBGE, 2014), enquanto no Brasil o percentual de pessoas que moram no campo gira em torno de $16 \%$, em Rondônia é de $26 \%$. Para se ter uma ideia da importância do espaço rural no estado, dos 52 municípios de Rondônia, 23 têm a maioria da população residindo no campo, com alguns municípios, inclusive, tendo 70\% ou mais de sua população fora do ambiente urbano, como em Ministro Andreazza (70\%), Alto Alegre do Parecis (71\%), Corumbiara (71\%), Vale do Paraíso (72\%), Campo Novo de Rondônia (73\%), Castanheiras (76\%), São Felipe do Oeste (76\%), Governador Jorge Teixeira (78\%), Nova União (79\%), Theobroma (81\%) e Novo Horizonte do Oeste (83\%) (IBGE, 2014).

Esse contingente expressivo da população convive com vários problemas, mas só a título de exemplo, apontamos o ínfimo preço dos produtos e a dificuldade de escoamento da produção devido às péssimas estradas. Ao longo dos anos, apesar da grande migração de jovens para as cidades, comprometendo o próprio desenvolvimento da agricultura familiar como prática social, esses desafios vão sendo de alguma forma remediados, com mobilizações e reivindicações junto ao poder público, criação de associações para beneficiamento e venda dos produtos e mudanças no plantio para produtos mais demandados pela população urbana. Porém duas situações são mais desafiadoras: o acesso a uma saúde pública de qualidade; uma educação que respeite as suas especificidades e possa de alguma forma auxiliar nas práticas sociais cotidianas. Apesar da importância de se discutir a questão da saúde pública no estado, o foco deste trabalho será a Educação do Campo ${ }^{3}$ do município de Ji-Paraná a partir de algumas questões que nos chamaram a atenção no II Seminário de Educação do Campo, promovido pela Secretaria de Educação do Município (SEMED) em agosto de 2014 (JI-PARANÁ, 2014).

Este trabalho, problematizado a partir do campo epistemológico dos Estudos Culturais, que "[...] têm estado há muito tempo preocupado com o terreno cotidiano das pessoas e com todas as formas pelas quais as práticas culturais falam a suas vidas e de suas vidas" (NELSON; TREICHLER; GROSSBERG, 2013, p. 25), objetiva discutir, num primeiro momento, a ausência dos agricultores num seminário que diz respeito à educação de sua família, a partir da ideia de que a "A Educação do Campo não é para nem apenas com, mas sim, dos camponeses [...]" (CALDART, 2012, p. 263, grifos da autora). Num segundo momento, objetiva inventariar e analisar que caminhos pedagógicos os professores das escolas do campo do município de Ji-Paraná, RO, apontam para uma mudança no sentido de fortalecimento das ações educativas no campo do município. Os professores posicionaram-se a partir da questão que pode ser assim enunciada: que práticas curriculares devem ser desenvolvidas para o fortalecimento da Educação do Campo? Essa questão faz parte do Documento Anexo I, sob o título Encaminhamentos Gerais do II Seminário de Educação do Campo do município.

\footnotetext{
${ }^{3}$ Diferente de educação rural, que sempre foi instituída pelos organismos oficiais e teve como propósito a escolarização como instrumento de adaptação do homem ao mundo do trabalho urbano (OLIVEIRA; CAMPOS, 2012), "A Educação do Campo [e no campo] nomeia um fenômeno da realidade brasileira atual, protagonizado pelos trabalhadores do campo e suas organizações, que visa incidir sobre a política de educação desde os interesses sociais das comunidades camponesas" (CALDART, 2012. p. 259, grifos da autora).
} 
Apesar de outras duas questões terem sido discutidas e apontamentos terem sido feitos pelos professores por retratarem o que tem sido a educação rural no Brasil ao longo dos anos, apenas as descreveremos sem problematizá-las. A primeira foi sobre as práticas curriculares existentes que dificultam o trabalho na Educação do Campo, e a segunda, sobre as práticas curriculares existentes que fortalecem a Educação do Campo. Portanto, neste trabalho, a partir das ideias de Hall (1997; 2011), Silva (2012; 2013), Santomé (2013), Giroux (2013) Nelson, Treichler e Grossberg (2013) e Arroyo (2014), as discussões recairão sobre as proposições (prospectivas) para uma Educação do Campo a partir de professores que, em sua maioria, moram no espaço urbano e hodiernamente se deparam com os desafios postos por quem é forjado pelas práticas sociais camponesas.

\section{POR QUE NEGAR AOS AGRICULTORES O DIREITO DE PENSAR A EDUCAÇÃO DE SEUS FILHOS?}

O município de Ji-Paraná, segundo mais populoso do estado de Rondônia, possui uma população estimada em 129.242 habitantes (IBGE, 2014) e tem uma concentração bem menor no campo do que a grande maioria dos 52 municípios. Inferimos que o solo do município, assim como o da grande maioria do estado, é considerado impróprio para o plantio de lavouras anuais. Cim (2003, p. 9) afirma que "[...] apenas $17 \%$ do solo do estado é apropriado para o plantio, o restante da terra é infértil, não é apropriada para germinar". Talvez por isso, mais do que em outros municípios do interior do estado, a agricultura não seja a base da economia de Ji-Paraná, como se observa a partir do Censo do IBGE (2010), que aponta os serviços respondendo por $70 \%$, as pequenas indústrias por $21,4 \%$ e a agricultura por apenas $8,6 \%$.

Nessa perspectiva, apesar de o município não apresentar um índice grande de agricultores como o dos outros municípios do interior do estado, como vimos acima, o Censo do IBGE de 2010 aponta que $10 \%$ dos habitantes de Ji-Paraná estão no meio rural. Apesar de ser um índice baixo perante os números apresentados, não significa que esses quase 13.000 sujeitos não precisem acessar a educação como um direito humano. Essa discussão torna-se necessária, a nosso ver, em função de que os agricultores, ao longo da história da educação brasileira, foram decretados como inexistentes, com a grande maioria não tendo acesso ao "latifúndio do saber", como afirma Arroyo (2014). Por isso, num primeiro momento, à luz das problematizações dos Estudos Culturais, que, como afirmam Nelson, Treichler e Grossberg (2013, p. 17), "[...] têm tentado se conectar a problemas sociais e políticos reais", neste trabalho problematizamos o fato de um seminário que tinha como objetivo refletir sobre a prática curricular que atenda às necessidades da escola campesina e levantar propostas de implementação de programas, metodologias e estratégias para o atendimento à população do campo, enfim, reformular a Educação do Campo no município de Ji-Paraná, não contou com a participação daqueles para quem as ações estavam sendo discutidas, no caso, os agricultores que residem nas linhas vicinais ${ }^{4}$.

Os agricultores de Ji-Paraná, distribuídos em 6.896 .782 km², têm acesso a quatro escolas em nível de Educação Infantil e a 11 escolas ${ }^{5}$ em nível de Ensino Fundamental, chamadas polos

\footnotetext{
${ }^{4}$ Estradas vicinais são vias de acesso às pequenas vilas, fazendas e sítios ou caminhos que ligam povoações relativamente pequenas e próximas (DEPARTAMENTO NACIONAL DE INFRAESTRUTURA DE TRANSPORTES [DNIT], 2007). Em Rondônia, essas estradas, chamadas linhas, não possuem pavimentação asfáltica, sendo, em sua grande maioria, intrafegáveis no tempo chuvoso.

${ }^{5}$ http://www.ji-parana.ro.gov.br/layout2013/index2.php?ver_pagina=endescolas
} 
(municipais), onde se concentram alunos de comunidades rurais do entorno e até mesmo mais distantes por meio do transporte escolar. No entanto, como se observa pelos números dos Indicadores Demográficos e Educacionais (IDE) (BRASIL, 2011), essas escolas parecem não conseguir mobilizar os alunos do campo para o ensino que vêm ministrando. Só a título de exemplo, no 2 a ano do Ensino Fundamental em 2010, o percentual de reprovação dos alunos do campo foi de $16,90 \%$, e o dos alunos das escolas urbanas, de $10,60 \%$. Seriam os alunos do campo menos capazes do que os citadinos para aprender? Ou se trataria de um ensino descolado dos interesses dos agricultores, que não veem na escola utilidade para as práticas sociais que encampam e os constituem? Para Ribeiro (2012), o problema desse baixo rendimento explica-se:

Os filhos dos camponeses experimentam uma necessidade maior de aproximação entre o trabalho e o estudo, visto que a maior parte deles ingressa cedo nas lidas da roça para ajudar a família, de onde se retira a expressão agricultura familiar. Mas na escola apenas se estuda, e este estudo nada tem a ver com o trabalho que o camponês desenvolve com a terra. (RIBEIRO, 2012, p. 296).

Giroux (2013), ao falar da recusa dos Estudos Culturais em desvincular a dinâmica da política e do poder do processo de escolarização, também nos ajuda a problematizar o que vem ocorrendo nas escolas feitas para o campo e não com o campo, as quais não têm conseguido desafiar os sujeitos a quem elas se destinam, quando afirma que "para os Estudos Culturais a educação gera um espaço narrativo privilegiado para alguns/algumas estudantes e, ao mesmo tempo, produz um espaço que reforça a desigualdade e a subordinação para outros/as [...]" (GIROUX, 2013, p. 84).

A não-participação nas discussões num seminário que objetiva avaliar a educação à qual têm direito, ao mesmo tempo em que novos rumos serão sinalizados, revela a negação de um preceito legal. A Resolução n. 2 de abril de 2008, que estabelece as Diretrizes Complementares, Normas e Princípios para o Desenvolvimento de Políticas Públicas de Atendimento da Educação Básica do Campo, afirma em seu Artigo 6으, inciso primeiro, que a organização e o funcionamento das escolas do campo respeitarão as diferenças entre as populações atendidas quanto à sua atividade econômica, seu estilo de vida, sua cultura e suas tradições (BRASIL, 2008 ).

Esse preceito legal está distante da realidade aqui analisada. Há, como se observa, o reconhecimento, por parte dos responsáveis pela viabilização de uma educação que atenda aos agricultores, de que a educação à qual estes têm direito não é oferecida, pois está distante das práticas sociais que forjam os sujeitos do campo. A secretária municipal de Educação do município, na abertura do evento, afirmou: "infelizmente, o poder público não consegue mobilizar o campo" (SILVA; LIMEIRA, 2014). O poder público do município, por meio de sua representante, sabe que a educação não tem correspondido aos anseios dos camponeses, negando suas identidades. Ainda na abertura do evento, a secretária afirmou: "temos muito a aprender com o povo do campo. Que vejamos mais que números, que vejamos as pessoas, pois infelizmente não temos políticas públicas voltadas para a valorização do homem no campo". Mas não seria o Seminário uma oportunidade de ouvir os sujeitos do campo e, a partir deles, de suas experiências culturais, de suas necessidades formativas, começar a delinear essas políticas? Por que o poder público não os vê como capazes de se colocar como sujeitos de conhecimentos e de pensar suas identidades e suas culturas? Arroyo (2014, p. 13) afirma: "as vítimas dessas brutais e persistentes pedagogias, ao afirmarem-se presentes, desocultam as pedagogias de inferiorização, subalternização, que pretenderam destruir seus saberes, valores, memórias, culturas, identidades coletivas". 
Portanto, apesar de existirem algumas práticas curriculares já ligadas à participação do agricultor, como se observa no documento Anexo 1 - Encaminhamentos Gerais do Seminário, que, segundo os professores, fortalecem a Educação do Campo - como, por exemplo, o projeto integração escola-comunidade, diálogo aberto com a comunidade, valorização do conhecimento da comunidade local na aplicabilidade dos projetos e relação família e escola -, elas mantêm um caráter homogeneizante. Elas são concebidas e pensadas pela escola não levando em conta a diferença e a identidade camponesa. Com isso, tendem a ser naturalizadas, cristalizadas, essencializadas (SILVA, 2012). Esse processo, gestado a partir da escola sem a participação dos agricultores, envolve relações de poder, inclusive, como afirma Woodward (2012), o poder para definir quem é incluído e quem é excluído. A homogeneização dá-se também, segundo Ribeiro (2012), porque para esses sujeitos, quando existe uma escola na área onde vivem, é oferecida uma educação na mesma modalidade ofertada às populações que vivem nas cidades, esquecendo-se de que, na perspectiva da Educação do Campo, os projetos de educação nascem das demandas formuladas pelos sujeitos sociais e por eles articuladas e desenvolvidas, conforme apontam Sant'Anna e Marques (2015).

Chama-nos a atenção uma escola ter citado que um dos elementos que dificultam as práticas curriculares nas escolas do campo é a falta de comprometimento da família com a educação dos filhos. Como a família poderia participar se os projetos, quando existem, são estranhos às suas práticas culturais e, nas práticas curriculares, os agricultores têm sido vistos até hoje como ignorantes, como aqueles cujos conhecimentos são considerados inúteis sob a ótica de quem pensa e faz a educação para eles? Como se observa, nada é feito por eles mesmos, mas em seus nomes (CALDART, 2012). Isso mostra, como diz Silva (2012, p. 81), que "[...] o poder de definir a identidade e de marcar a diferença não pode ser separado das relações mais amplas de poder. A identidade e a diferença não são, nunca, inocentes". Pensar uma educação a partir dos agricultores é valorizar a sua forma de organizar-se, seu trabalho, sua luta por direitos e políticas públicas. É ser capaz de pensá-los como diferentes, não operando no sentido de fixar uma identidade como a norma, pois, segundo Woodward (2012), essa é uma das formas privilegiadas de hierarquização das identidades e das diferenças.

\section{OS PROFESSORES SINALIZAM O QUE ENTENDEM SEREM PRÁTICAS CURRICULARES IMPORTANTES PARA O FORTALECIMENTO DA EDUCAÇÃO DO CAMPO NO MUNICÍPIO}

Antes de entrarmos na discussão das práticas curriculares sugeridas pelos professores que poderiam fortalecer a Educação do Campo no município, faremos algumas considerações mais gerais sobre as discussões encampadas no evento, deixando claro que essa iniciativa de problematizar a Educação do Campo no município por parte de seus responsáveis já é uma sinalização de que algo está sendo engendrado, promovendo inquietude e abrindo possibilidades de rompimento com a educação rural. Esta, como afirmam Oliveira e Campos (2012, p. 240), "[...] sempre foi instituída pelos organismos oficiais e teve como propósito a escolarização como instrumento de adaptação do homem ao produtivismo e à idealização de um mundo do trabalho urbano [...]".

Essa iniciativa começou em 2013, quando da realização do I Seminário de Educação do Campo, proposto pela Secretaria Municipal de Educação (SEMED) de Ji-Paraná. Mesmo que ainda não consiga promover mudanças qualitativas visando a uma organização curricular com centralidade nos sujeitos do campo e em suas vivências constitutivas de suas identidades, inferimos 
ser um avanço. As discussões estão sendo realizadas em parceria com outras organizações que, de alguma forma, estão contribuindo nas discussões com experiências diferentes tendo como público alvo os outros pensados como "inferiores" (ARROYO, 2014), como o Centro Familiar de Formação por Alternância (CEFFAs) de Ji-Paraná, mais conhecido como EFA-Itapirema, a Federação dos Trabalhadores na Agricultura (FETAGRO) e a Fundação Universidade Federal de Rondônia (UNIR), que tem, no Campus de Rolim de Moura, a experiência da formação de professores para o campo por meio do curso de licenciatura em Educação no Campo.

Consideramos importante nessas discussões a participação dos coletivos populares, como o CEFFAs e a FETAGRO, pois "esses coletivos mostram que as concepções e práticas educativas pensadas para educá-los, civilizá-los estão condicionadas pelas formas de pensá-los, ou pelo padrão de poder/saber de como foram pensados para serem subalternizados" (ARROYO, 2014, p. 11). Nessa perspectiva, buscam, mediante suas ações, deslocar as demandas políticas para o contexto em que as identidades sociais dos coletivos populares vão sendo produzidas. A partir da ideia de que uma proposta pedagógica para o campo deve priorizar a relação do sujeito com os artefatos culturais com os quais produz a sua existência, os sujeitos produzem-se com outros pertencimentos identitários, forjados na luta pela sobrevivência num contexto eminentemente agropecuário. Portanto, os agricultores, historicamente abandonados ou à mercê de políticas assistencialistas ou da obsoleta educação rural, uma caricatura da escola urbana, "[...] ficarão propensos a construir e cercar os pequenos refúgios onde podem ancorar e depositar as suas destituídas e frágeis identidades", como afirma Bauman (2005, p. 53).

Quanto à universidade pública responsável pela formação da grande maioria dos professores do município, sua presença num Seminário de Educação do Campo pode ser considerada um avanço, pois, na maioria das vezes, esteve confinada a uma prática formativa de professores "dando aulas", função que parece sintetizar sua missão propedêutica. Esse paradigma de formação, que há muito tempo não satisfaz os acadêmicos, está com suas estruturas abaladas. Green e Bigun (2013, p. 208) afirmam que, nas instituições escolares, os jovens são cada vez mais alienígenas: "o espectro do pós-modernismo assombra os lugares anteriormente sagrados pelos quais nossa própria geração uma vez se movimentou com grande confiança, como o tinha feito a geração antes de nós". Para que essas academias aulistas não desapareçam, precisam sair dos intramuros onde se abrigaram até hoje. Nesse sentido, parece que está havendo minimamente na UNIR uma abertura, uma reinvenção dos modos de produzir conhecimentos, procurando responder aos desafios postos pela contemporaneidade. Começa a haver um entendimento de que "as instituições escolares são lugares de luta, e a pedagogia pode e tem que ser uma forma de luta político-cultural" (SANTOMÉ, 2013, p. 170) também na formação dos professores. A universidade precisa, portanto, de acordo com Silva (2012, p. 100) ao falar de uma política pedagógica e curricular da identidade e da diferença, "[...] colocar no seu centro uma teoria que permita não simplesmente reconhecer e celebrar a diferença e a identidade, mas questioná-las".

Antes de enumerarmos e analisarmos as práticas curriculares apontadas pelos professores que, segundo eles, devem ser desenvolvidas para o fortalecimento da Educação do Campo no município, um questionamento poderia ser feito: para os professores o que seriam essas práticas curriculares? Como as pensam? Entendemos que isso se faz necessário porque, dentre as sugestões visando a esse fortalecimento, aparecem, por exemplo, melhorias e manutenção das estradas e pontes, construção de quadras poliesportivas, festival de músicas do campo, uma pessoa para cuidar da horta e projeto de arborização. Como isso pode vir a compor ou tem com- 
posto o projeto pedagógico das escolas? Não estamos negando que esses elementos podem ser importantes e que poderiam fazer parte da vida não só da escola, mas também da comunidade local. Mas seriam essas as práticas curriculares que ajudariam a fortalecer a Educação do Campo no município? ou seriam apenas mais um disfarce que mascara e transfere do espaço escolar para o espaço geográfico-natural-social as responsabilidades pelo não-protagonismo camponês nas escolas do campo? Sinalizar que os problemas da Educação do Campo são de ordem externa ao projeto da escola implica não ter esses elementos como artefatos culturais que podem vir a fazer parte do currículo para ajudar os agricultores a analisar e compreender as estruturas sociais que fixam suas identidades. A educação continua sendo pensada como se não tivesse, para os sujeitos a quem ela se destina, um significado cultural e político, não pensando em estratégias e linhas de atuação para que se torne libertadora (SANTOMÉ, 2013).

Em relação às práticas curriculares existentes que dificultam o trabalho na educação do campo, apontamos, a partir do Documento Anexo 1 - Encaminhamentos do Seminário, algumas ações que ocorrem nas escolas e que, segundo os professores, não têm contribuído na formação dos sujeitos do campo. Citamos algumas por entendermos que nos ajudam a pensar as questões pedagógicas marcantes que des/caracterizam as práticas das escolas do campo no município e contribuem na produção das identidades de seus sujeitos: livros didáticos fora da realidade do campo; falta de materiais didático-pedagógicos; falta de formação para professores que atuam na educação do campo e de um currículo específico que amplie o conteúdo rural; falta de espaços adequados para o desenvolvimento do currículo; estrutura da escola não voltada para as atividades do campo; falta de conscientização e incentivo da comunidade escolar; estradas ruins do município e pontes sem manutenção; obrigatoriedade de cumprir a grade curricular, calendários, carga horária; ausência de oficina prática; aulas só dentro de sala; livros não relacionados com a realidade do campo e outros materiais inadequados; falta de profissional na área de técnicas agropecuárias com formação específica; falta de comprometimento das famílias com as atividades escolares; falta de biblioteca; defasagem idade/série; déficit de funcionários para atender a programas específicos (não disseram quais); espaço físico inadequado; professores em salas multisseriadas; imigração de alunos (urbano x rural) e falta de comprometimento da família.

Os apontamentos dos professores revelam um retrato fiel do que as escolas do campo vivenciaram ao longo dos anos. Esse discurso é constitutivo dos sujeitos do campo. As ações são para eles e nunca com eles, como foi dito: não estão "conscientizados", não se "comprometem" e não incentivam as práticas escolares. Assim vão sendo forjadas as identidades dos sujeitos do campo; como diz Silva (2013), quem tem o poder de representar tem o poder de definir e determinar a identidade. Desse modo, na busca da constituição da identidade hegemônica, as práticas educativas não têm sido muito eficazes - reprovações, evasões - porque os agricultores também são seres interpretativos, instituidores de sentido, como defende Hall (1997) ao falar da centralidade da cultura na produção das identidades.

Da mesma forma que mencionamos as práticas curriculares existentes que têm dificultado o trabalho na Educação do Campo, citamos, de forma sucinta, as práticas curriculares já existentes que, na ótica dos professores, o fortalecem. Essas são ações que, segundo os professores, vêm dando certo. Inferimos que são componentes curriculares em que o nexo entre representação e poder se realiza e se efetiva, como aponta Silva (2013): projeto horta na escola; produção de biofertilizante e compostagem; visita e participação na feira agroindustrial de Ji-Paraná; visita a propriedades locais com piscicultura para aula prática; projeto integração entre escola e comu- 
nidade; disciplina de técnica agropecuária; horta na escola; projetos com aulas práticas; valorização do conhecimento da comunidade local na aplicabilidade dos projetos; diálogo aberto à comunidade; formação continuada; gestão democrática; parceria com órgãos públicos que dão assistência ao agricultor; projeto mata ciliar; Projeto Programa Educacional de Resistência às Drogas (Proerd); projeto Um Computador por Aluno (UCA); projeto horta na escola; adequação do conteúdo à realidade de vida do educando; frequência, assiduidade e comprometimento dos professores e demais profissionais da educação; alimentação de boa qualidade; implantação do Programa Mais Educação, Pacto Nacional pela Alfabetização na Idade Certa (PNAIC) e outros.

Como se observa, são muitas as ações consideradas práticas curriculares exitosas, e não citamos todas às quais os sujeitos se referem por não diferirem muito. Uma olhada menos acurada dá a impressão de que o que está sendo feito já é um grande avanço, e talvez não o deixe de ser. Porém, do que foi apontado, o que vem ao encontro da perspectiva legal enunciada nas Diretrizes Operacionais para a Educação Básica nas Escolas do Campo (BRASIL, 2002), que afirmam que a identidade das escolas do campo é definida pela sua vinculação às questões inerentes à sua realidade, ancorando-se na temporalidade e saberes próprios dos estudantes? Inferimos que seriam essas ações profícuas se constitutivas dos projetos pedagógicos das escolas e se estes fossem construídos entre a escola e os camponeses a partir de suas práticas e artefatos culturais, mas não elaborados, como historicamente se tem visto, por especialistas que buscam aproximá- los da vivência camponesa, sem tomar suas práticas sociais como possibilidades de produção de outras identidades que não as hegemônicas. Ao pensar-se o currículo para o campo, como vimos, ignora-se o preceito legal, visto que, no artigo 4으 das Diretrizes Operacionais já citadas, está posto que a construção dos projetos político-pedagógicos das escolas do campo se constituirá num espaço público de investigação e articulação de experiências e estudos direcionados para o mundo do trabalho (BRASIL, 2002).

As práticas curriculares efetivadas podem constituir-se em um dispositivo importante para a produção de identidades hegemônicas, pois os professores e o corpo técnico-pedagógico podem tomar a si próprios como pontos de referência (WOODWARD, 2012), assim contribuindo para produzir identidades de acordo com as suas condições materiais e sociais. Nessa perspectiva, como o poder está inscrito no interior do currículo, segundo defende Silva (2013), pode-se afirmar que as ações descritas pelos professores têm operado no sentido de produzir identidades camponesas que partilham dos mesmos sistemas de significação com os quais a instituição escolar opera.

Mas quais seriam as propostas feitas pelos professores de práticas curriculares que devem ser desenvolvidas para o fortalecimento da educação do campo em Ji-Paraná?

Apesar de algumas se repetirem, observamos que, dentre as quase 50 sugestões feitas, apenas uma, embora apareça três vezes, foi no sentido de uma proposta curricular voltada para a realidade camponesa: adequação do currículo e projetos que contemplem a realidade do campo (JI-PARANÁ, 2014). Entretanto os professores não sinalizam se essa adequação seria feita com a participação dos sujeitos a quem esse currículo e esses projetos se destinam. Não seria esse adequar para e não construir com uma forma de tentar impor processos educativos que anulam, desconsideram os processos históricos nos quais os agricultores foram se constituindo? Para Arroyo (2012, p. 233), "a teoria pedagógica é obrigada a entender a diversidade das formas de controle, de exploração do trabalho e de apropriação dos produtos do trabalho e da terra, associadas à produção histórica dos diversos como desiguais" - mas isso não aparece como um imperativo nas práticas curriculares a serem efetivadas para o fortalecimento da educação no 
município. Considerando, como evidencia Woodward (2012, p. 11), que "uma das formas pelas quais as identidades estabelecem suas reivindicações é por meio do apelo a antecedentes históricos", os agricultores continuam ignorados em seus saberes, à mercê de propostas curriculares que não permitem se afirmarem como sujeitos políticos, posto que não participam efetivamente de sua elaboração.

Uma sugestão dos professores que nos chama a atenção é a atribuição ao poder público de forjar políticas públicas para o campo, quando no evento deveriam apontar práticas curriculares para o fortalecimento da educação dos agricultores. Apesar da indissociabilidade entre políticas de educação e práticas de educação, não seria essa sugestão uma forma de evitar uma política de educação a partir do compromisso docente de criar outras formas de pensar o campo e seus sujeitos? Não seria esquivar-se de uma responsabilidade que, na prática, é dos que mediante um projeto pedagógico têm hodiernamente a incumbência de educar as crianças e jovens do campo? Não haveria nessa sugestão o reconhecimento da não-formação para as diferenças culturais dos sujeitos do campo que pressionam para que suas presenças sejam valorizadas no espaço escolar? Ou está implícito o entendimento de que a responsabilidade de formulação de um currículo para o campo não pode ser dos agricultores, já que são "carentes"? - uma forma de não-reconhecimento, segundo Arroyo (2014).

Nas proposições feitas, aparece com alguma frequência a necessidade de materiais didático-pedagógicos desenvolvidos para a realidade do campo, tais como: livros didáticos voltados para a realidade da região; aquisição de material didático voltado para a realidade camponesa; e material diversificado e espaço físico que favoreçam o desenvolvimento do currículo. Qual seria a efetiva contribuição desses materiais no fortalecimento da Educação do Campo? Como os agricultores poderão reconhecer-se nos processos inferiorizantes com que foram pensados a partir de uma proposta gestada e colocada em prática em que os materiais parecem ser a solução? Isso mostra, como aponta Arroyo (2014, p. 33), que "as pedagogias escolares são as mais cercadas e fechadas a definir critérios rígidos de validade e até de não reconhecimento dos saberes, modos de pensar e de pensar-se, de aprender e de educar-se que os educandos levam às escolas [...]". Uma proposta que ignora a diversidade de processos de formação/humanização dos agricultores e propõe o uso de elementos exteriores à cultura destes transforma-se, como diz Arroyo (2014), numa antipedagogia.

Os professores parecem ignorar que há preceitos legais sinalizando que, na oferta de educação para o campo, devem ser levados em conta o interesse e as necessidades dos sujeitos. Como se lê, na LDB 9.394/96, em seu Art. 28, no inciso I, os sistemas de ensino deverão propor "conteúdos curriculares e metodologias apropriadas às reais necessidades e interesses dos alunos da zona rural"; no inciso III do mesmo artigo, propõe-se adequação dos conteúdos à natureza do trabalho na zona rural (BRASIL, 1996). Quais seriam essas necessidades, interesses e o tipo de trabalho com os quais os agricultores produzem suas identidades? Como fazer isso sem fazer um inventário dos artefatos culturais da realidade camponesa? Lembramos, com Woodward (2012, p. 42), que "cada cultura tem suas próprias e distintivas formas de classificar o mundo. É pela construção de sistemas classificatórios que a cultura nos propicia os meios pelos quais podemos dar sentido ao mundo social e construir significados".

Sobre fazer um inventário das práticas culturais dos agricultores visando a torná-las ponto de partida para uma Educação do Campo, causa-nos estranheza a sugestão de a escola ter a liberdade de fazer uma pesquisa de campo para detectar a realidade da comunidade. Por que 
isso não pode ser feito pela comunidade escolar? Quem impede dizendo que assim não deve ser feito? Por que não levar em consideração, como dissemos acima, as Diretrizes Operacionais para a Educação Básica nas Escolas do Campo, que afirmam que a identidade da escola do campo é definida pela sua vinculação às questões inerentes à sua realidade (BRASIL, 2002)? Inferimos que isso se dá em função de que, na prática docente, sempre se trabalhou com manuais, receituários, livros didáticos a serem seguidos pelos alunos guiados pelos professores, num processo histórico de fabricação de identidades a serem fixadas como "normais". Segundo Silva (2012), a normalização é um dos processos mais sutis pelos quais o poder se manifesta no campo da identidade e da diferença. Para Arroyo (2014, p. 51), produzimos os outros "[...] como Outros marginais, excluídos, oprimidos, inconscientes". Esse processo já está enraizado na educação brasileira, visto que essas brutais pedagogias de produzir inexistentes foram ensaiadas e persistem em nossa história desde a colonização (ARROYO, 2014).

Outra sugestão que aparece três vezes como necessária para o fortalecimento da educação camponesa em Ji-Paraná é a parceria com outros órgãos que trabalham com as questões agropecuárias no município. Acreditamos que isso se torna importante, uma vez que a soma de esforços, a diversificação de enfoques e as experiências com o trabalho agropecuário poderão contribuir com a família em suas práticas sociais, inclusive melhorando a produção na agricultura familiar. Mas como isso será feito? Como serão pensadas e organizadas as parcerias tendo em vista a formação das crianças e jovens do campo do município? Que conteúdos serão produzidos? Que relação terão com a riqueza cultural dos agricultores? Como se articulam com as identidades dos trabalhadores? Tais questionamentos se dão porque essas parcerias produzirão narrativas a partir da formação e experiências dos profissionais, interferindo no processo de subjetivação dos sujeitos do campo. Segundo Silva (2012), isso ocorre porque as narrativas, ao produzirem significados, são cruzadas pelas linhas do poder, mas elas não existem num campo tranquilo de imposição. "Através das narrativas, identidades hegemônicas são fixadas, formadas e moldadas, mas também contestadas, questionadas, disputadas" (SILVA, 2012, p. 199).

Outra sugestão, que aparece cinco vezes, sobre a qual consideramos importante tecer alguns comentários, é a de formação de professores principalmente para lidar com as questões técnicas em agropecuária. Os próprios professores sugerem para a Secretaria de Educação do Município "manter formação continuada do professor de forma que garantam ao profissional o trabalho em áreas específicas (arte, técnicas, etc.) de forma a atender a diversidade local" (JI-PARANÁ, 2014).

Nessa perspectiva, precisamos pensar que os agricultores do interior do estado de Rondônia, ao longo dos anos, estão sendo produzidos mediante a prática da agricultura de subsistência, não dispondo de conhecimentos técnicos capazes de ajudá-los na melhoria da produção agropecuária. Os órgãos públicos de assistência não têm conseguido muito êxito nessa empreitada. Como esse modelo arcaico de plantios anuais não gera lucros, os filhos ainda jovens acabam migrando para as cidades em busca de maiores possibilidades de trabalho. Contudo, por não terem qualificação para o trabalho urbano, acabam no subemprego. Assim, à medida que os sistemas de significação e representação cultural se multiplicam, os jovens migrantes são confrontados por uma multiplicidade desconcertante e cambiante de identidades possíveis (HALL, 2011).

Apesar de entendermos a premente necessidade da formação dos educadores, pensamos que não será qualquer formação que vai contribuir na produção de uma educação diferente no 
campo. É preciso, como esclarece Arroyo (2012), romper com a formação de um protótipo único, genérico, de docente-educador para a educação básica. Se isso não ocorrer, como geralmente não ocorre nos cursos de formação de professores propostos pelas universidades, é preciso que a própria Secretaria de Educação do Município encampe a luta por uma educação continuada, conforme sugerem os professores, para um exercício docente que respeite a multiplicidade desconcertante e cambiante de identidades possíveis (HALL, 2011) dos agricultores. Para Arroyo (2012, p. 361),

Sem a superação desse protótipo único, genérico de docente, as consequências persistem: a formação privilegia a visão urbana, vê os povos-escolas do campo como uma espécie em extinção, e privilegia transportar para as escolas do campo professores da cidade sem vínculos com a cultura e os saberes dos povos do campo.

Esse processo acaba por formar um professor que em sua prática não percebe, como afirma Hall (2011) ao falar da identidade na pós-modernidade, que a identidade do homem camponês plenamente unificada, completa, segura e coerente não existe.

Outras sugestões para o fortalecimento da Educação do Campo em Ji-Paraná foram feitas, mas acreditamos que as propostas aqui analisadas já nos dão uma dimensão do grande desafio que têm pela frente os comprometidos com um projeto que leve em conta as práticas culturais que forjam os agricultores. Há necessidade premente de um esforço conjunto para entender a pedagogia não como "[...] uma técnica ou um conjunto de habilidades neutras, [mas como] uma prática cultural que só pode ser compreendida através de questões sobre a história, política, poder e cultura" (GIROUX, 2013, p. 85).

\section{CONSIDERAÇÕES FINAIS}

Os Encaminhamentos Gerais do Seminário, como observamos, não têm muito de inovador, apesar do esforço da Secretaria de Educação e de professores em dar visibilidade à educação do agricultor do município de Ji-Paraná. Houve avanços a partir do primeiro Seminário, realizado em 2013, como podemos constatar a partir da descrição das práticas curriculares já existentes que fortalecem a Educação do Campo no município. Entretanto, como a própria secretária admite no seu discurso de abertura, muita coisa ainda há por ser feita, e talvez o desafio maior seja o de romper com o pressuposto didático-pedagógico da educação rural, mesmo que a secretária tenha clareza de que "temos muito a aprender com o povo do campo. Que vejamos mais que números, que vejamos as pessoas, pois infelizmente não temos políticas públicas voltadas para a valorização do homem no campo".

Essa dificuldade não é só da Educação do Campo de Ji-Paraná e tem sido pauta de discussão desde que, na década de 1990, os movimentos sociais encamparam a luta por uma educação que desse legitimidade às práticas sociais que forjam as identidades dos sujeitos do campo, principalmente dos agricultores pobres. Portanto, apesar de extremamente louvável o empreendimento de traçar novos rumos para a educação dos agricultores do município, observa-se que as propostas de práticas curriculares que devem ser desenvolvidas para o fortalecimento da Educação do Campo aprovadas no evento pelos presentes carregam os ranços de uma educação fundada nos moldes daquela pensada para o público urbano. Segundo Sant’anna e Marques (2015, p. 730), "a educação urbana, tomada como referência, não considera a diversidade sociocultural das populações que vivem no campo, seus saberes e modos de produção de vida". 
Dessa forma, pode-se afirmar que somente haverá avanço no projeto educativo do campo se a educação à qual os sujeitos têm acesso e que os constitui não for apenas uma educação para nem apenas com, mas sim, dos camponeses (CALDART, 2012). Ela precisa ser construída por eles mesmos a partir de suas práticas e artefatos culturais. Acreditamos que assim nasceria um currículo antimarginalização (SANTOMÉ, 2013) no qual a cultura camponesa estaria presente em todas as atividades acadêmicas. Isso porque a análise dos conteúdos desenvolvidos até hoje mostra que, nas escolas, no "[...] que é enfatizado nas propostas curriculares, chama fortemente atenção a arrasadora presença das culturas que podemos chamar de hegemônicas" (SANTOMÉ, 2013, p. 167).

A problematização do seminário realizado pela Secretaria de Educação foi com o intuito de contribuir para pensar um novo projeto educativo para o campo, buscando subsídios que nos deem condições de responder ao questionamento de Silva (2013, p. 192): "como as identidades sociais hegemônicas podem ser contestadas e subvertidas?" Acreditamos que as identidades do campo continuam sendo padronizadas a partir das sugestões feitas no evento para o fortalecimento da Educação do Campo no município. Esse projeto, que se quer inovador, não permitirá que os agricultores disponham de estruturas importantes de poder (SANTOMÉ, 2013) que thes permitam lutar contra a estereotipia que os tem anulado ao longo de nossa história, nem que construam condições de produzir identidades e diferenças do campo não subalternizadas.

\section{REFERÊNCIAS}

ARROYO, Miguel G. Outros sujeitos, outras pedagogias. 2. ed. Petrópolis, RJ: Vozes, 2014.

Diversidade. In: CALDART, Roseli Salete et al. (Org.). Dicionário da educação do campo. Rio de Janeiro, São Paulo: Escola Politécnica de Saúde Joaquim Venâncio, Expressão Popular, 2012. p. 232-8.

BAUMAN, Zygmunt. Identidade. Entrevista a Benedetto Vecchi. Tradução de Carlos Alberto Medeiros. Rio de Janeiro: Jorge Zahar, 2005.

BRASIL. Índice Demográfico Educacional - IDE. 2011. Rondônia, RO. Disponível em: <http://ide.mec.gov. br/2011/estados/relatorio/uf/11>. Acesso em: 15 maio 2015.

Lei CNE/CEB n. 2. Diretrizes complementares, normas e princípios para o desenvolvimento de políticas públicas de atendimento da Educação Básica do Campo. Brasília, 28 de abril de 2008.

. Resolução CNE/CEB n. 1, de 3 de abril de 2002. Institui Diretrizes Operacionais para a Educação Básica das Escolas do Campo. Brasília, 2002.

. Lei n. 9.394, de 20 de dezembro de 1996. Estabelece as Diretrizes e Bases da Educação Nacional. Diário Oficial da República Federativa do Brasil, Brasília, dez. 1996.

CALDART, Roseli Salete. Educação do campo. In: CALDART, Roseli Salete et al. (Org.). Dicionário da educação do campo. Rio de Janeiro, São Paulo: Escola Politécnica de Saúde Joaquim Venâncio, Expressão Popular, 2012. p. 259-67.

CIM, Salvador. O processo migratório de ocupação no Estado de Rondônia. Visão histórica. Primeira Versão, Porto Velho, RO, ano II, n. 104, v. VII, jun. 2003. Disponível em: <http://www.primeiraversao.unir. br/atigos_pdf/numero104Cinn.pdf>. Acesso em: 12 maio 2015.

DEPARTAMENTO NACIONAL DE INFRAESTRUTURA DE TRANSPORTES (DNIT). Diretoria de Planejamento e Pesquisa. Coordenação Geral de Planejamento e Programação de Investimentos. Terminologias Rodoviárias Usualmente Utilizadas. Brasília, 2007. 
GIROUX, Henri A. Memória e pedagogia no maravilhoso mundo da Disney. In: SILVA, Tomaz Tadeu da (Org.). Alienígenas na sala de aula. Uma introdução aos estudos culturais em educação. 11. ed. Petrópolis, RJ: Vozes, 2013. (Coleção Estudos Culturais em Educação).

GREEN, Bill; BIGUN, Chris. Alienígenas na sala de aula. In: SILVA, Tomaz Tadeu da (Org.) Alienígenas na sala de aula. Uma introdução aos estudos culturais em educação. 11. ed. Petrópolis, RJ: Vozes, 2013. (Coleção Estudos Culturais em Educação).

HALL, Stuart. A identidade cultural na pós-modernidade. Tradução de Tomaz Tadeu da Silva e Guacira Lopes Louro. 11. ed. Rio de Janeiro: DP\&A, 2011.

. A centralidade da cultura: notas sobre as revoluções culturais do nosso tempo. In: THOMPSON, Kenneth (Org.). Media and cultural regulation. London, Thousand Oaks; New Delhi: The Open University; SAGE Publications, 1997. Cap. 5. Publicado em Educação \& Realidade com a autorização do autor. Disponível em: <http://www.ufrgs.br/neccso/word/texto_stuart_centralidadecultura.doc>. Acesso em: 27 mar. 2014.

INSTITUTO BRASILEIRO DE GEOGRAFIA E ESTATÍ́STICA (IBGE). Estimativa de população 2014. Cidades. Rondônia. Ji-Paraná. Disponível em: <http://www.ibge.gov.br/home/estatistica/populacao/estimativa2014/ estimativa_tcu.shtm>. Acesso em: 5 jun. 2015.

. Sinopse do Censo Demográfico 2010 - Rondônia. Disponível em: <http://www.censo2010.ibge. gov.br/sinopse/index.php?uf=11\&dados=0>. Acesso em: 2 jun. 2015.

JI-PARANÁ, Município [de]. II Seminário de Educação do Campo. 21 de agosto de 2014. Anexo IEncaminhamentos Gerais. Ji-Paraná, RO: EFA-Itapirema, 2014.

NELSON, Cary; TREICHLER, Paula A.; GROSSBERG, Lawrence. Estudos culturais: uma introdução. In: SILVA, Tomaz Tadeu da (Org.). Alienígenas na sala de aula. Uma introdução aos estudos culturais em educação. 11. ed. Petrópolis, RJ: Vozes, 2013. (Coleção Estudos Culturais em Educação).

OLIVEIRA, Lia Maria T. de; CAMPOS, Marília. Educação básica do campo. In: CALDART, Roseli Salete et al. (Org.). Dicionário da educação do campo. Rio de Janeiro, São Paulo: Escola Politécnica de Saúde Joaquim Venâncio, Expressão Popular, 2012. p. 239-46.

RIBEIRO, Marlene. Educação rural. In: CALDART, Roseli Salete et al. (Org.). Dicionário da educação do campo. Rio de Janeiro, São Paulo: Escola Politécnica de Saúde Joaquim Venâncio, Expressão Popular, 2012. p. 295-301.

SANT'ANNA, Paulo Afrânio; MARQUES, Luiz Otávio Costa. Pibid Diversidade e a formação de educadores do campo. Educação \& Realidade, Porto Alegre, v. 40, n. 3, p. 725-44, jul./set. 2015. Disponível em: <http:// www.seer.ufrgs.br/index.php/educacaoerealidade/article/view/45795/34276>. Acesso em: 20 jul. 2015.

SANTOMÉ, Furjo Torres. As culturas negadas e silenciadas no currículo. In: SILVA, Tomaz Tadeu da (Org.). Alienígenas na sala de aula. Uma introdução aos estudos culturais em educação. 11. ed. Petrópolis, RJ: Vozes, 2013. (Coleção Estudos Culturais em Educação).

SILVA, Adrielen Amâncio da; LIMEIRA, Eronilda de Souza. // Seminário de Educação do Campo (Relatório). Escola Família Agrícola, Ji-Paraná, agosto de 2014.

SILVA, Tomaz Tadeu da. Currículo e identidade social: territórios contestados. In: SILVA, Tomaz Tadeu da (Org.). Alienígenas na sala de aula. Uma introdução aos estudos culturais em educação. 11. ed. Petrópolis, RJ: Vozes, 2013. (Coleção Estudos Culturais em Educação).

. A produção social da identidade e da diferença. In: SILVA, Tomaz Tadeu da (Org.). Identidade e diferença. A perspectiva dos estudos culturais. 12. ed. Petrópolis, RJ: Vozes, 2012.

WOODWARD, Kathryn. Identidade e diferença: uma introdução teórica e conceitual. In: SILVA, Tomaz Tadeu da (Org.). Identidade e diferença. A perspectiva dos estudos culturais. 12. ed. Petrópolis, RJ: Vozes, 2012. 


\section{Sobre os autores:}

Alberto Dias Valadão: Professor da Universidade Federal de Rondônia (UNIR), Campus de JiParaná- DCHS. Mestre em Psicologia pela UNIR. Tem experiência na área de Educação, com ênfase em Fundamentos da Educação. Doutorando em Psicologia pela Universidade Católica Dom Bosco (UCDB), Linha de Pesquisa Políticas Públicas, Cultura e Produções Sociais. Dezessete anos de experiência na adoção da Pedagogia da Alternância em Rondônia, como Monitor, Coordenador Pedagógico e Diretor na Escola Família Agrícola Itapirema de Ji-Paraná. Experiência como professor em Especialização Lato Sensu em disciplinas como: Pedagogia das Competências, Fundamentos do Serviço de Supervisão Escolar e Psicologia do Desenvolvimento e da Aprendizagem. Desenvolve Projetos de Pesquisa e Extensão em Educação do Campo e Psicologia com ênfase em formação docente. E-mail: ad.valadao@bol.com.br

José Licínio Backes: Graduado em Filosofia. Mestre e Doutor em Educação pela Universidade do Vale do Rio dos Sinos (UNISINOS ). Pós-doutoramento em Educação pela Universidade do Minho, Portugal. Membro do quadro permanente de docentes do Programa de Pós-Graduação em Educação - Mestrado e Doutorado, da UCDB, na Linha de Pesquisa Diversidade Cultural e Educação Indígena, exercendo atividades de pesquisa, orientação de mestrado e doutorado e ensino. Docente do Programa de Pós-Graduação em Psicologia - Mestrado de Doutorado da mesma instituição. Bolsista Produtividade-CNPq. E-mail: backes@ucdb.br 